\title{
The change of motivational spectrum during anaesthesiology residency and the relation to job satisfaction: Self-determination theory in anaesthesiology
}

\author{
Parisa Moll-Khosrawi ( $\sim$ pmollkho@icloud.com ) \\ Universitatsklinikum Hamburg-Eppendorf https://orcid.org/0000-0003-2024-0020 \\ Stefan Zimmermann \\ Universitatsklinikum Hamburg-Eppendorf \\ Christian Zöllner \\ Universitatsklinikum Hamburg-Eppendorf \\ Leonie Schulte-Uentrop \\ Universitatsklinikum Hamburg-Eppendorf
}

\section{Research article}

Keywords: Self-determination, motivation, job-satisfaction

Posted Date: August 28th, 2019

DOl: https://doi.org/10.21203/rs.2.13293/v1

License: (9) (1) This work is licensed under a Creative Commons Attribution 4.0 International License. Read Full License 


\begin{abstract}
Background: Job satisfaction remains a manifold goal in all fields of the working world, as well as in anaesthesiology. Since Selfdetermination theory (SDT) has been introduced by Deci and Ryan a lot of studies have been coducted, answering the question how motivation influences job satisfaction. It has been shown that intrinsic motivation and autonomous regulation lead not only to job satisfaction, but to better job performance. However, the roles of extrinsic motivation and controlled regulation and their effects on affect, job performance and job satisfaction have not been worked out clearly. No investigation has been done so far, analysing motivation of anaesthesiologists. Method: A cross-sectional study design was chosen to assess situational motivation and jobsatisfaction, within a sample of anaesthesiologists, applying the Situational Motivation Scale. Differences of motivational expression in residents of different training years, attendings and consultants were analysed, as well as the correlation of motivational quality with job-satisfaction. Results: The invested group showed the same pattern throughout the motivational continuum, with consultants reporting the highest levels of intrinsic $(6.02,0.44)$, identified $(5.78,0.71)$ and introjected $(4.69,0.80)$ regulation. The consultants showed the highest computed controlled $(3.29,0.64)$ and autonomous motivation index $(5.90,0.55)$. The lowest intrinsic motivation was found in the group of attendings $(5.70,0.92)$. Job satifaction was correlated with intrinsic motivation $(0.0360, p<0.01)$ and negatively correlated with amotivation $(-0.265, \mathrm{p}<0.05)$. Conclusion: Intrinsic motivation and autonomous regulation are necessary for achieving job satisfaction, the presence of controlled regulation and extrinsic behavioural regulation have no declining effects on job satisfaction but their expression might rather be even required for it. The Situational Motivation Scale proved its applicabilty to assess health care providers'motivational qualities and therefore can be considered for staff-talks and used as indirect predicotors of healt care providers'well-being and job-satisfaction.
\end{abstract}

\title{
Background
}

Many medical departments are facing challenges to provide job satisfaction for residents, combined with a threatening lack of doctors (1). Additionally, the young staff members that are joining departments, called "generation Y", are known to be well-educated, optimistic but demanding (1). Nevertheless, employees need to have a high job satisfaction, which might be impaired by natural characteristics of the job, like night shifting (2) or low levels of autonomy in residency. How can job satisfaction be provided despite to daily burdens, and which factors influence job satisfaction?

To answer these questions, particularly in anaesthesiology, a closer look into motivational aspects of residents, attendings and consultants is inevitable.

First we need to know if there are any changes of motivation taking place during residency, then eventual interventions can be considered. The goal should be to allocate high job satisfaction and high levels of motivation, resulting in good job efficacy.

Whenever motivation is mentioned, Self-determination theory (SDT) is the leading theory in this field since it has been introduced by Deci and Ryan (3).

SDT is based on the postulation that humans have an innate will to grow and this tendency to grow can be supported or hampered by intrinsic or extrinsic factors or situations. The psychological growth of human beings is determined by three basic psychological needs: Autonomy, competency and relatedness.

Other than in the motivation theory of Porter and Lawler, who have a dichotomous description of motivation in intrinsic and extrinsic, SDT specifies motivation on a scale and describes different forms that can guide individual behaviour $(3,4)$. Every motivation underlies a type of regulation, regulatory process and locus of causality.

Figure 1 schematically shows the SDT, in which integrated regulation, the most self-determined form of extrinsic motivation, is excluded, because it was not assessed in this study.

\section{Figure 1. Schematic depiction of Self-determination Theory (Adapted by Ten Cate, 2011)}

When an activity is carried out due to inherent satisfaction, usually intrinsic motivation is present - SDT associates this with cognitive and social development. Therefore, intrinsic motivated individuals are autonoumously regulated. When an activity is conducted due to external sources, such as punishment or reward, extrinsic motivation is foregrounded. Four types of extrinsic motivation are described in SDT, which vary in terms of their relative autonomy, as extrinsically motivated behaviour is regulated differently (3): External

Page 2/12 
regulated behaviour is least autonomous, it is only based on demands or punishment or possible rewards (5). Introjected regulation is more autonomous than external regulation, but still the activity or rule is seen as conditioned by others $(5,6)$. When it comes to avoid guilt and attain self-esteem and citing ego, the predominant regulation is of introjected nature. Introjected regulation is predominant to avoid guilt, attain self-esteem and citing ego $(3,6-8)$. Moving on the continuous motivational scale, identified regulation is more autonomous than introjected regulation: here the action is accepted as important and involves consciously valuing a goal $(8,9)$. When regulations are connected to oneself, the most autonomous form of extrinsic regulation, integrated regulation occurs $(5,6,8)$. Integrated regulation shares qualities with intrinsic motivation, although classified as extrinsic. Nevertheless intrinsic, integrated and identified regulation are called „autonomous self- regulation”, whereas extrinsic and introjected regulation are summerized as „controlled self-regulation”.

Having no motivation at all is referred to as amotivation, which can occur if a person experiences lack of competence or does not see the reason for a task $(3,10)$.

It has been demonstrated that intrinsic motivation is associated with the satisfaction of the three basic needs $(11,12)$. Several studies revealed that rewards may even impair intrinsic motivation, moving it more to extrinsic motivation, but there are also existing investigations that doubt this phenomenon (13-15). Furthermore, Gillet et al. showed that rewards did not have any influence on external regulation (15).

Studies in different fields like physical exercise, education health care and work place have shown that autonomous self-regulation leads to academic achievement (16), positive emotions (17), perceived competence and self-worth (18), creativity (19), retention and less drop out of activities or school attendance $(10,20)$, better performance on complex tasks $(21)$ and correlates with greater job satisfaction and well being $(9,22-26)$. In addition, employees who are autonomously regulated are less at risk for burn-out (27). Regarding the work place, controlled self-regulation is associated with more turnover and burn-out $(28,29)$.

The basic psychological needs can not be satisfied by all means in the work setting and intrinsic motivation is less likely to occur at the work place than in hobbies (11). Work motivation is largely influenced by the social context in which employees operate and their motivation is not only affected by resources but also by job demands (30). Autonomy supportive environments at work have lead to better well-being and enhanced autonomous self-regulation $(12,22,31)$ and decision making autonomy minimized negative effects of job demands (27).

The nature of anaesthesiology residency is characterized by low autonomy and low decision-making at the beginning, accompanied by the fact that if emergencies occur, the specialists take over and residents may feel a lack of competence, leading to amotivation (9). Furthermore, at the beginning of residency, tasks become mundane. The question that arises in the context of anaesthesiology residency is if the mentioned circumstances have any effect on motivation in anaesthesiology residents, attendings or consultants?

The goal of this study was to analyze the distribution of motivation within a sample of different year anaesthesiology residents, in attendings and consultants, facing different working routine and responsibilities. Further, we analyzed if the described correlation between job satisfaction and motivational regulation is valid for anaesthesiologists as well. The applicability, validity and internal consistency of the broadly used Situational motivation scale was analysed for the field of health care providers, specifically anaesthesiologists.

\section{Methods}

\section{Study Design and setting}

This study was performed at the Department of Anaesthesiology in the University Medical Center of Hamburg-Eppendorf, Germany. A cross-sectional study design was chosen to measure the situational motivation in different stages of residency (in attendings and consultants). An email with information about the study was sent in May 2018 to all anaesthesiologists of the department $(n=186)$, including a questionnaire which they were asked to fill out and to return anonymously within a time span of two weeks. The questionnaire included a question to assess job satisfaction and a german translated version (32) (see Additional file figure 2) of the Situation Motivation Scale (SIMS) (33), adapted by Gillet and co-workers (15), which measures participants' situational motivation towards performing a task, in our study, anaesthesiology.

71 questionnaires (38\%) were returned. 


\section{Participants}

All anaesthesiologists of the department $(n=186)$ were eligible for the study as no specific eligible criteria were necessary and a broad cross-sectional design was chosen.

A detailed description of the departments' organisational and personnel structure and job descriptions of the investigated subgroups are provided in the Additional file (Additional file table 1).

\section{Variables (Questionnaire)}

To avoid cognitive bias, participants were asked not to fill out the questionnaire during or directly after night-shift $(2,34)$.

- Participants' situational motivation towards performing anaesthesiology was measured using a translated version (german) of the Situation Motivation Scale (SIMS) (33), adapted by Gillet et al. (15). The SIMS has four subscales, measuring the type of motivation to run an activity at a specific point of time (33) and studying the important question why an individual shows a certain behaviour (35). Consequently, it is possible to compare the motivational measurement with its conceptual definition that refers to the recognised reason of task engagement $(10,36,37)$. The adapted version of the SIMS has five subscales, with four items per subscale, measuring intrinsic motivation, extrinsic-, indentified-, introjected regulation and amotivation. Each item has a 7-point Likert scale ( 1 = "Does not correspond at all" and 7 = "Corresponds exactly") and participants were asked to specify the extent to which each item represented a reason why they were performing anaesthesiology.

- A computed autonomous motivation index was calculated by adding and averaging the intrinsic motivation and indentified regulation, and a controlled motivation index was computed by adding and averaging extrinsic- and introjected motivation ( 15 , 33). Validity and reliability of the SIMS, as well as of the adapted version, have been confirmed in several studies $(15,33,38)$.

- Job satisfaction was assessed by a 7-point Likert scale ( 1 = "Not satisfied" and 7 = "Completely satisfied").

There are no specific cut-off values for the subscales of the SIMS, describing if a type of motivation is too low. However, the scores can be interpreted in regard to interindividual differences. Therefore, we did not divide the results in high or low categories and just compared the mean values of motivational subscales between different years of anaesthesiology residency, attendings and consultants.

The same principle was used to analyse the job satisfaction results - the higher the score, the higher the job satisfaction was categorized.

\section{Statistical analysis}

Statistical analysis was performed using IBM SPSS Statistics Version 23.0. No data was missing in the returned questionnaires. Internal consistency of the adapted german version was analyzed, calculating cronbach alphas for each subscale. Mean differences in situational motivation and job satisfaction were compared by year of anaesthesiology residency in an analysis of variance (ANOVA). Significant differences between the different groups were analyzed by a follow-up post hoc test (Bonferroni).

\section{Results}

\section{Characteristics of study participants}

A total of 71 anaesthesiologists of our department took part in the study and finished the questionnaire containing the SIMS scale. The reasons for non-participation were not assessed, as participation was voluntary. We assumed that main reasons for non-participation were absence during the study period (a.e ICU rotation, vacation, scheduling in other OR than in the central OR of the department with distance to the collection box). Table 1 shows the training level of the participants.

\section{Table 1. Anaesthesiology state of training of study participants}




\begin{tabular}{|r|r|r|r|r|r|}
\hline No. of participants & $\mathbf{1}^{\text {st }}$ \& $2^{\text {nd }} \mathbf{y r}$ & $3^{\text {rd }} \mathbf{y r}$ & $\mathbf{4}^{\text {th }}$ \& $\mathbf{5}^{\text {th }} \mathbf{y r}$ & Attending & Consultant \\
\hline & 17 & 15 & 17 & 12 & 10 \\
\hline
\end{tabular}

\section{Distribution of motivation and internal consistency of the german version of Situational Motivation Scale}

The levels of internal consistency of the SIMS subscales were satisfactory, with Cronbach alpha ranges from 0.79 to 0.68 (39), implying a good applicability of the SIMS. The results from the ANOVA revealed that there were no significant differences of motivational distribution within the different years of residency, attendings and consultants, except for controlled and introjected regulation (table 2, fig.2).

\section{Table 2. Internal consistency, means (standard deviation) of different situational motivational variables and job satisfaction and ANOVA results}

\begin{tabular}{|c|c|c|c|c|c|c|c|c|c|c|}
\hline \multicolumn{2}{|c|}{$\begin{array}{l}\text { Crohnbach } \\
\text { alpha }\end{array}$} & 0.72 & 0.68 & 0.71 & 0.79 & 0.75 & & & & \\
\hline \multirow[t]{3}{*}{ ANOVA } & $\eta^{2}$ & .03 & .07 & .20 & .08 & \multicolumn{2}{|l|}{.06} & .04 & .15 & .12 \\
\hline & $\mathrm{p}$ & .79 & .28 & .01 ** & .26 & \multicolumn{2}{|l|}{.41} & .59 & $.03 *$ & .11 \\
\hline & $\begin{array}{l}F \\
\text { (df) }\end{array}$ & $0.41(4)$ & $1.31(4)$ & $4.11(4)$ & $1.34(4)$ & \multicolumn{2}{|l|}{$1.01(4)$} & $0.71(4)$ & $2.89(4)$ & $1.95(4)$ \\
\hline \multicolumn{2}{|c|}{ Consultant } & $\begin{array}{l}6.02 \\
(0.44\end{array}$ & $\begin{array}{l}5.78 \\
(0.71)\end{array}$ & $\begin{array}{l}4.69 \\
(0.80)^{\mathrm{A}}\end{array}$ & $\begin{array}{l}1.89 \\
(0.82)\end{array}$ & \multicolumn{2}{|l|}{$1.58(0.51)$} & $5.90(0.55)$ & $\begin{array}{l}3.29 \\
(0.64)^{B}\end{array}$ & $5.78(0.44)$ \\
\hline \multicolumn{2}{|c|}{ Attending } & $\begin{array}{l}5.70 \\
(0.92)\end{array}$ & $\begin{array}{l}4.81 \\
(1.10)\end{array}$ & $3.38(1.04)$ & $\begin{array}{l}1.78 \\
(0.75)\end{array}$ & \multicolumn{2}{|l|}{$2.00(0.78)$} & $5.26(0.95)$ & $\begin{array}{l}2.57 \\
(0.63)\end{array}$ & $4.83(1.64)$ \\
\hline \multicolumn{2}{|c|}{$4^{\text {th }}$ and $5^{\text {th }}$ year } & $\begin{array}{l}5.99 \\
(0.77)\end{array}$ & $\begin{array}{l}5.29 \\
(1.08)\end{array}$ & $\begin{array}{l}2.80 \\
(1.40)^{A}\end{array}$ & $\begin{array}{l}1.75 \\
(0.78)\end{array}$ & \multicolumn{2}{|l|}{$1.57(0.72)$} & $5.63(0.79)$ & $\begin{array}{l}2.26 \\
(0.96)\end{array}$ & $\begin{array}{l}5.29 \\
(0.77)\end{array}$ \\
\hline \multicolumn{2}{|l|}{$3^{\text {rd }}$ year } & $\begin{array}{l}5.87 \\
(0.68)\end{array}$ & $\begin{array}{l}5.38 \\
(0.88)\end{array}$ & $\begin{array}{l}3.30 \\
(0.94)^{A}\end{array}$ & $\begin{array}{l}1.82 \\
(0.93)\end{array}$ & \multicolumn{2}{|l|}{$1.83(0.84)$} & $5.63(0.72)$ & $\begin{array}{l}2.55 \\
(0.68)\end{array}$ & $4.91(0.79)$ \\
\hline \multicolumn{2}{|c|}{$1^{\text {st }}$ and $2^{\text {nd }}$ year } & $\begin{array}{l}5.69 \\
(1.23)\end{array}$ & $\begin{array}{l}5.51 \\
(1.20)\end{array}$ & $3.60(1.28)$ & $\begin{array}{l}2.47 \\
(1.56)\end{array}$ & \multicolumn{2}{|l|}{$2.11(1.32)$} & $5.60(1.16)$ & $\begin{array}{l}3.03 \\
(1.10)\end{array}$ & $5.64(1.00)$ \\
\hline \multicolumn{2}{|c|}{$\begin{array}{l}\text { Situational } \\
\text { Motivation }\end{array}$} & Intrinsic & Identified & Introjected & Extrinsic & Amotivation & $\begin{array}{l}\text { motivation } \\
\text { indices }\end{array}$ & autonomous & controlled & $\begin{array}{l}\text { Job } \\
\text { satisfaction }\end{array}$ \\
\hline
\end{tabular}


Table 2. Internal consistency, means (standard deviation) of different situational motivational variables and job satisfaction and ANOVA results

Fig 2. Situational motivation variables and job satisfaction for each investigated group.

As shown in figure 2 and table 2, all investigated groups showed similar patterns throughout the motivational continuum. Nevertheless, consultants had the highest expression of intrinsic motivation, identified motivation and yet autonomous regulation. On the other end of the motivational continuum, consultants reported highest level of introjected motivation and controlled regulation and lowest level of amotivation. First year residents showed highest level of extrinsic regulation and amotivation, although the results were not significantly different. Attendings' intrinsic motivation and autonomous regulation were reported at the lowest level comparing within the group.

The highest score of job satisfaction was found within the consultants and the lowest level was reported by attendings.

\section{Relationship between situational motivation and job satisfaction}

Correlations between the subscales of the Situational Motivation Scale and the computed autonomous and controlled motivation were analysed, as well as the correlation between job satisfaction and each subscale of the SIMS.

Table 3. zero-order correlations among study variables.

\begin{tabular}{|c|c|c|c|c|c|c|c|c|}
\hline & Situational motivation & 2. & 3. & 4. & 5. & 6. & 7. & 8. \\
\hline 1. & intrinsic & $0.694 * *$ & 0.154 & $-0.323^{* *}$ & $-0.637 * *$ & -0.79 & $0.903^{* *}$ & 0.360 ** \\
\hline 2. & identified & & $0.313^{\star *}$ & 0.24 & $-0.354^{\star *}$ & 0.23 & $0.936^{\star *}$ & 0.21 \\
\hline 3. & introjected & & & $0.239 *$ & 0.118 & $0.826^{* *}$ & $0.262^{*}$ & 0.28 \\
\hline 4. & extrinsic & & & & $0.401 *$ & $0.745^{\star *}$ & -0.144 & $-0,218$ \\
\hline \multirow[t]{2}{*}{5.} & amotivation & & & & & $0.309 * *$ & $-0.523^{\star *}$ & $-0.265^{*}$ \\
\hline & \multicolumn{8}{|l|}{ Motivation indices } \\
\hline 6. & Controlled regulation & & & & & & 0.099 & -0.110 \\
\hline \multirow[t]{2}{*}{7.} & Autonomous regulation & & & & & & & $0.299 *$ \\
\hline & Job satisfaction & & & & & & & \\
\hline
\end{tabular}

${ }^{\star *} \mathrm{p}<0.01,{ }^{*} \mathrm{p}<0.05$ 
These correlations conformed with a simplex pattern of relationships across the investigated group of anaesthesiologists. Subscales adjacent along the motivational continuum of self-determination were more positively correlated than more distant ones. Situational introjected motivation was correlated to autonomous motivation, although, on the motivational continuum, it is subdivided to the controlled self regulation end, next to extrinsic motivation. Job satisfaction was correlated to situational autonomous motivation and negatively correlated to situational amotivation.

\section{Discussion}

In the present study we discovered that anaesthesiology residents in different years of training, attendings and consultants showed a similar pattern throughout the motivational continuum, described by the SDT. Consultants had significant higher levels of introjected motivation and controlled regulation in comparison to the investigated group of $3^{\text {rd }}$ year and $4^{\text {th }} / 5^{\text {th }}$ year residents. Job satisfaction differed not significantly within the groups but was positively correlated to intrinsic motivation and autonomously regulated behaviour and negatively correlated to amotivation.

To our best knowledge, we were the first group that conducted a motivational study in the field of anaesthesiology, or broadly speaked health care providers. Further, we could validate the SIMS not only for its german translation, but also for anaesthesiology employees.

Nevertheless, this study has some limitations: the sample size is small for each subgroup, being a potential source of bias. The study design was based on voluntary participation, which might lead to the assumption, that participating anaesthesiologists have a higher a priori intrinsic motivation. However, there is no way to rule out this speculation as these kind of studies can only be conducted voluntarily.

SDT is based on the postulation that humans have an innate will to grow and this tendency to grow can be supported or hampered by intrinsic or extrinsic factors or situations. The psychological growth of human beings is determined by three basic psychological needs: Autonomy, competency and relatedness. It has been demonstrated that intrinsic motivation is associated with the satisfaction of the three basic needs. $(11,12)$ Several studies revealed that rewards may even impair intrinsic motivation, moving it more to extrinsic motivation, but there are also existing investigations that doubt this phenomenon. (13-15)

Our findings can be explained as following: Consultants have the ability to create their working day more autonomously than residents, therefore they can influence plenty of working processes. Due to their completed anaesthesiology training and the consecutively gained expertise, they have a broad decision- making scope concerning medical issues, increasing autonomy and competence.

Earlier studies showed that intrinsic motivation was increased by actions that augment the feeling of competence, e.g. positive feedback. (40) Humans who experience the feeling of competence and autonomy are autonomously regulated in their actions and their motivation is of intrinsic nature. (41)

Our findings are congruent with the fact that consultants reported the highest expression of intrinsic motivation, even if this was not significant.

The investigated consultants reported not only the highest levels of intrinsic motivation and autonomous regulation, but also controlled regulation and introjected motivation were significantly higher compared to the other study subgroups. Introjected motivation and regulation are used to avoid guilt and attain pride and self-esteem. $(5-7,42)$

In other words, consultants were high on the whole motivational continuum, namely autonomous and controlled motivation. Plenty positive effects of autonomous regulation (satisfaction, well-being, mental balance) have been reported. $(22-25,43)$ Effects of controlled regulation were uncertain for a long period of time. $(13,44,45)$ Gillet and co-workers. reported that the manifestation of controlled regulation leads to negative affect, but did not have any influence on performance and job satisfaction. (15) Similar findings were demonstrated in a study conducted in China, in which employees who were high on autonomous and introjected motivation, were associated with more positive job characteristics and better psychosocial well-being, independently from their extrinsic regulation. (46) These findings were confirmed in sport science, where athletes' performance was better if motivation was reported upon the whole continuum. (44) Investigations on job perfectionism and workaholism revealed that employees with manifestations of motivation throughout the motivational continuum had higher levels of these features. $(47,48)$ These findings can be transferred to our results, as consultants are specialists and are promoted due to their outstanding performance. 
An alternative explanation for the high expression of consultants' controlled regulation might be, that consultants are also confronted with mundane tasks and it is reported, that for conducting mundane and daily tasks, the existence of controlled regulation leads to better performance $(22,49)$, at least for a short period of time.

Junior residents ( $1^{\text {st }}$ and $2^{\text {nd }}$ year) reported highest levels of amotivation and extrinsic motivation, even if not significant. Amotivation occurs when an individual experiences lack of competence and the reason for carrying out an activity and possible outcomes are not identified. $(4,10)$

The need for competence and personal causation are the relevant basis to initiate the identification process regarding a task and leading to intrinsic motivation. (50) The nature of anaesthesiology residency is characterized by low autonomy and low decisionmaking at the beginning, accompanied by the fact that if emergencies occur, the specialists take over and residents may feel a lack of competence, leading to amotivation. (9) Furthermore, at the beginning of residency, tasks become mundane. The junior residents might not see the locus of causality and personal causation in situative, delegated working tasks from inside. Therefore, the need for competence and autonomy are not completely satisfied in their daily work routine (a.e. important decisions are made by consultants and attendings), leading to the high extrinsic motivation levels. The „energizing basis” for intrinsic motivation as well as required nutriments for the natural process of internalization might be lacking and this might result into high levels of extrinsic and relative high levels of amotivation, coexisting to their reported levels of intrinsic motivation.

Job satisfaction was not reported significantly different within the investigated subgroups, it was only correlated to intrinsic motivation and autonomous controlled behaviour. Amotivation was negatively correlated to job satisfaction. Taking these results, extrinsic and controlled motivation are not subsequently disturbing, as long as they are coexisting with intrinsic or rather autonomous regulation.

One might argue, that the use of a pre-existing academic motivational scale (51) might have matched better for our investigation. Our aim was not to measure overall motivation, but rather the situational motivation, because the situative motivation focusses on the actual nature of motivation and equates the operationalization of motivation, regarding the "why" of behaviour. (35)

The generalisation of our findings is hard to evaluate, as different departments might provide various environmental influences on daily work tasks of anaesthesiologists. Work motivation is largely influenced by the social context in which employees operate and their motivation is not only affected by resources but also by job demands. (30) Autonomy supportive environments at work have lead to better well-being and enhanced autonomous self-regulation $(12,22,31)$ and decision making autonomy minimized negative effects of job demands. (27)

Nevertheless, our study might be one of the first of many to come, leading to an improvement or changes regarding the anaesthesiologists working life, by consideration of motivational aspects.

\section{Conclusion}

The SIMS showed a good applicability in anaesthesiologists and a good internal validity in its german version and is suitable to assess employees' existential orientation and hereby assess their well-being and job-satisfaction consequently.

For job satisfaction, intrinsic motivation and autonomous regulation are necessary, but the presence of controlled regulation and extrinsic behavioural regulation do not have declining effects on it - their expression might rather be even required for it as extrinsic motivation and controlled regulation might be helpfull for mundane and not outrageously challenging working conditions.

\section{Declarations}

\section{Ethical approval and consent to participate}

The local ethics committee of Hamburg (Ethikkommission der Ärztekammer Hamburg, Hamburg, Germany) was contacted with a detailed project description and it did not see any necessity of deliberation and approved the project. Participants declared their consent for anonymous analysis of the data with their participation

\section{Consent for publication}


Not applicable

\section{Availability of data and materials}

The datasets used and/or analysed during the current study are available from the corresponding author on reasonable request.

\section{Competing interests}

The authors declare that they have no competing interests" in this section.

\section{Funding}

This study was not supported by any funding.

\section{Authors' contributions}

PM-K made substantial contributions to conception and design, acquisition of data, analysis and interpretation of data. She has been involved in drafting the manuscript and given final approval of the version to be published. She agreed to be accountable for all aspects of the work in ensuring that questions related to the accuracy or integrity of any part of the work are appropriately investigated and resolved.

$S Z$ made substantial contributions to conception and design, analysis and interpretation of data. He has been involved in drafting the manuscript and revising it critically for important intellectual content. He has given final approval of the version to be published. He agreed to be accountable for all aspects of the work in ensuring that questions related to the accuracy or integrity of any part of the work are appropriately investigated and resolved.

$C Z$ made substantial contributions to conception and design, analysis and interpretation of data. He has been involved in drafting the manuscript and revising it critically for important intellectual content. He has given final approval of the version to be published. He agreed to be accountable for all aspects of the work in ensuring that questions related to the accuracy or integrity of any part of the work are appropriately investigated and resolved.

$L S-U$ made substantial contributions to acquisition of data. She has been involved in revising the manuscript critically for important intellectual content and has given final approval of the version to be published. She agreed to be accountable for all aspects of the work in ensuring that questions related to the accuracy or integrity of any part of the work are appropriately investigated and resolved.

\section{Acknowledgements}

We would like to thank the anaesthesiologists of the Department of Anaesthesiology, University Medical Center Hamburg Eppendorf, for participation.

\section{References}

1.Schlitzkus LL, Schenarts KD, Schenarts PJ. Is your residency program ready for Generation Y? Journal of surgical education. 2010;67(2):108-11.

2.Smith-Coggins R, Rosekind MR, Hurd S, Buccino KR. Relationship of day versus night sleep to physician performance and mood. Annals of emergency medicine. 1994;24(5):928-34.

3.Ryan RM, Deci EL. Self-determination theory and the facilitation of intrinsic motivation, social development, and well-being. American psychologist. 2000;55(1):68.

4.Ryan RM, Deci EL. Intrinsic and extrinsic motivations: Classic definitions and new directions. Contemporary educational psychology. 2000;25(1):54-67. 
5.Ntoumanis N. Motivational clusters in a sample of British physical education classes. Psychology of Sport and Exercise. 2002;3(3):177-94.

6.Wang CJ, Biddle SJ. Young people's motivational profiles in physical activity: A cluster analysis. Journal of Sport and Exercise Psychology. 2001;23(1):1-22.

7.Deci EL, Eghrari H, Patrick BC, Leone DR. Facilitating internalization: The self-determination theory perspective. Journal of personality. 1994;62(1):119-42.

8.Koestner R, Losier GF. Distinguishing three ways of being highly motivated: A closer look at introjection, identification, and intrinsic motivation. 2002.

9.Gagné M, Deci EL. Self-determination theory and work motivation. Journal of Organizational behavior. 2005;26(4):331-62.

10.Vallerand RJ, Fortier MS, Guay F. Self-determination and persistence in a real-life setting: Toward a motivational model of high school dropout. Journal of Personality and Social psychology. 1997;72(5):1161.

11.Baard PP. Intrinsic need satisfaction in organizations: A motivational basis of success in for-profit and not-for-profit settings. Handbook of self-determination research. 2002;2:255-75.

12.Baard PP, Deci EL, Ryan RM. Intrinsic Need Satisfaction: A Motivational Basis of Performance and Weil-Being in Two Work Settings 1. Journal of applied social psychology. 2004;34(10):2045-68.

13.Cameron J, Pierce WD, Banko KM, Gear A. Achievement-based rewards and intrinsic motivation: A test of cognitive mediators. Journal of Educational Psychology. 2005;97(4):641.

14.Deci EL, Koestner R, Ryan RM. A meta-analytic review of experiments examining the effects of extrinsic rewards on intrinsic motivation. Psychological bulletin. 1999;125(6):627.

15.Gillet N, Vallerand RJ, Lafreniere M-AK, Bureau JS. The mediating role of positive and negative affect in the situational motivationperformance relationship. Motivation and Emotion. 2013;37(3):465-79.

16.Reeve J. Self-determination theory applied to educational settings. 2002.

17.Ryan RM, Connell JP. Perceived locus of causality and internalization: Examining reasons for acting in two domains. Journal of personality and social psychology. 1989;57(5):749.

18.Ryan RM, Grolnick WS. Origins and pawns in the classroom: Self-report and projective assessments of individual differences in children's perceptions. Journal of personality and social psychology. 1986;50(3):550.

19.Amabile TM. Motivation and creativity: Effects of motivational orientation on creative writers. Journal of personality and social psychology. 1985;48(2):393.

20.Vallerand RJ, Blssonnette R. Intrinsic, extrinsic, and amotivational styles as predictors of behavior: A prospective study. Journal of personality. 1992;60(3):599-620.

21.Benware CA, Deci EL. Quality of learning with an active versus passive motivational set. American Educational Research Journal. 1984;21(4):755-65.

22.Ilardi BC, Leone D, Kasser T, Ryan RM. Employee and supervisor ratings of motivation: Main effects and discrepancies associated with job satisfaction and adjustment in a factory setting 1. Journal of Applied Social Psychology. 1993;23(21):1789-805.

23. Theorell T, Karasek R, Eneroth P. Job strain variations in relation to plasma testosterone fluctuations in working men-a longitudinal study. Journal of internal medicine. 1990;227(1):31-6.

24.Matteson MT, Ivancevich JM. Controlling work stress: Effective human resource and management strategies: Jossey-Bass; 1987. 
25.Sherman LW, Gartin PR, Buerger ME. Hot spots of predatory crime: Routine activities and the criminology of place. Criminology. 1989;27(1):27-56.

26.Ryan RM, Deci EL, Grolnick WS. Autonomy, relatedness, and the self: Their relation to development and psychopathology. Ariel. 1995;128(151.189):155.

27.Fernet C, Guay F, Senécal C. Adjusting to job demands: The role of work self-determination and job control in predicting burnout. Journal of vocational behavior. 2004;65(1):39-56.

28.Fernet C, Senécal C, Guay F, Marsh H, Dowson M. The work tasks motivation scale for teachers (WTMST). Journal of Career assessment. 2008;16(2):256-79.

29.Richer SF, Blanchard C, Vallerand RJ. A motivational model of work turnover. Journal of Applied Social Psychology.

2002;32(10):2089-113.

30.Fernet $\mathrm{C}$, Gagné $\mathrm{M}$, Austin S. When does quality of relationships with coworkers predict burnout over time? The moderating role of work motivation. Journal of Organizational Behavior. 2010;31(8):1163-80.

31.Bono JE, Judge TA. Self-concordance at work: Toward understanding the motivational effects of transformational leaders. Academy of Management Journal. 2003;46(5):554-71.

32.Knörzer L, Brünken R, Park B. Facilitators or suppressors: Effects of experimentally induced emotions on multimedia learning. Learning and Instruction. 2016;44:97-107.

33.Guay F, Vallerand RJ, Blanchard C. On the assessment of situational intrinsic and extrinsic motivation: The Situational Motivation Scale (SIMS). Motivation and emotion. 2000;24(3):175-213.

34.Dula DJ, Dula NL, Hamrick C, Wood GC. The effect of working serial night shifts on the cognitive functioning of emergency physicians. Annals of emergency medicine. 2001;38(2):152-5.

35.McClelland DC. How motives, skills, and values determine what people do. American psychologist. 1985;40(7):812.

36.Deci E, Ryan RM. Intrinsic motivation and self-determination in human behavior: Springer Science \& Business Media; 1985.

37. Harter S. A new self-report scale of intrinsic versus extrinsic orientation in the classroom: Motivational and informational components. Developmental psychology. 1981;17(3):300.

38.Standage M, Gillison F, Treasure DC. Self-determination and motivation in physical education. 2007.

39.Streiner DL. Starting at the beginning: an introduction to coefficient alpha and internal consistency. Journal of personality assessment. 2003;80(1):99-103.

40.Deci E. Intrinsic motivation. New York, NY, US. Plenum Press. http://dx/. doi. org/10.1007/978-1-4613-4446-9; 1975.

41.Reeve J. Motivating others: Nurturing inner motivational resources: Allyn \& Bacon; 1996.

42.Sheldon KM, Elliot AJ. Not all personal goals are personal: Comparing autonomous and controlled reasons for goals as predictors of effort and attainment. Personality and Social Psychology Bulletin. 1998;24(5):546-57.

43.McGraw KO. The detrimental effects of reward on performance: A literature review and a prediction model. The hidden costs of reward: New perspectives on the psychology of human motivation. 1978:33-60.

44.Chantal Y, Guay F, Dobreva-Martinova T, Vallerand RJ. Motivation and elite performance: An exploratory investigation with Bulgarian athletes. 1996.

45.Konheim-Kalkstein YL, Van den Broek P. The effect of incentives on cognitive processing of text. Discourse Processes. 2008;45(2):180-94. 
46.Moran CM, Diefendorff JM, Kim T-Y, Liu Z-Q. A profile approach to self-determination theory motivations at work. Journal of Vocational Behavior. 2012;81(3):354-63.

47.Stoeber J, Davis CR, Townley J. Perfectionism and workaholism in employees: The role of work motivation. Personality and Individual Differences. 2013;55(7):733-8.

48.van Beek I, Taris TW, Schaufeli WB. Workaholic and work engaged employees: Dead ringers or worlds apart? Journal of occupational health psychology. 2011;16(4):468.

49.Grolnick WS, Ryan RM. Autonomy in children's learning: an experimental and individual difference investigation. Journal of personality and social psychology. 1987;52(5):890.

50.Vansteenkiste M, Zhou M, Lens W, Soenens B. Experiences of autonomy and control among Chinese learners: Vitalizing or immobilizing? Journal of educational psychology. 2005;97(3):468.

51.Vallerand RJ, Pelletier LG, Blais MR, Briere NM, Senecal C, Vallieres EF. The Academic Motivation Scale: A measure of intrinsic, extrinsic, and amotivation in education. Educational and psychological measurement. 1992;52(4):1003-17.

Figures

\begin{tabular}{|c|c|c|c|c|c|}
\hline \multirow{2}{*}{$\begin{array}{l}\text { Quality of } \\
\text { behaviour } \\
\text { Type of } \\
\text { motivation }\end{array}$} & \multicolumn{4}{|c|}{$\begin{array}{l}\text { Non-self determined } \\
\text { (controlled) }\end{array}$} & $\begin{array}{l}\text { Self-determined } \\
\text { (autonomous) }\end{array}$ \\
\hline & Amotivation & & Extrinsic & & Intrinsic \\
\hline $\begin{array}{l}\text { Type of } \\
\text { regulation }\end{array}$ & $\begin{array}{l}\text { Non- } \\
\text { regulation }\end{array}$ & External & Introjected & Identified & Intrinsic \\
\hline $\begin{array}{l}\text { Regulatory } \\
\text { processes }\end{array}$ & $\begin{array}{l}\text { Incompetence } \\
\text { Non- } \\
\text { intentional } \\
\text { lack of control }\end{array}$ & $\begin{array}{l}\text { - External } \\
\text { rewards } \\
\text { and } \\
\text { punishments } \\
\text { - Compliance }\end{array}$ & $\begin{array}{c}\text { - Internal rewards } \\
\text { and punishments } \\
\text { - Ego involvement }\end{array}$ & $\begin{array}{l}\text {-Identification with } \\
\text { the task } \\
\text { - Awareness } \\
\text { - Congruence }\end{array}$ & $\begin{array}{l}\text { Inherent } \\
\text { and } \\
\text { intrinsic } \\
\text { satisfactic } \\
\text { and } \\
\text { interest }\end{array}$ \\
\hline $\begin{array}{l}\text { Perceived } \\
\text { locus of } \\
\text { causality }\end{array}$ & Impersonal & External & $\begin{array}{l}\text { Somewhat } \\
\text { external }\end{array}$ & $\begin{array}{l}\text { Somewhat } \\
\text { internal }\end{array}$ & Internal \\
\hline
\end{tabular}

Figure 1

Schematic depiction of Self-determination Theory (Adapted by Ten Cate, 2011)

\section{Supplementary Files}

This is a list of supplementary files associated with this preprint. Click to download.

- SupplementBMCANA247.docx 